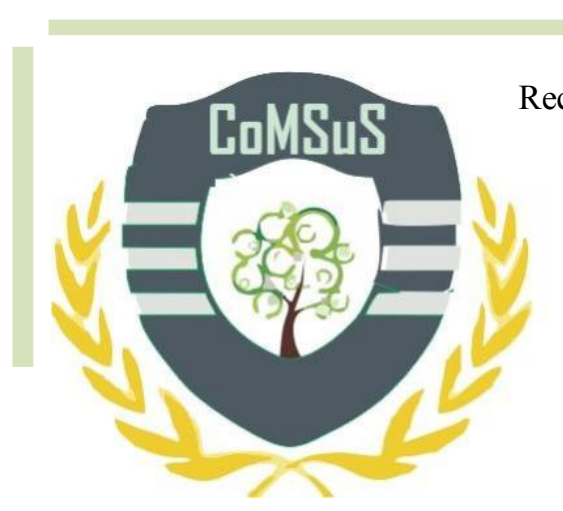

Recebido em 13/07/2018. Aprovado em 29/12/2018. Publicado em 28/02/2019.

Editor: Dr. Ivano Ribeiro

Processo de Avaliação: Double Blind Review - SEER/OJS

e-ISSN: $2359-5876$

DOI: $\underline{10.5935 / 2359-5876.20180008}$

\title{
INSERÇÃO DO PROCESSO SUCESSÓRIO NO PLANEJAMENTO ESTRATÉGICO DE UMA ASSOCIAÇÃO DE LOJAS DE MÓVEIS
}

\section{INSERTION OF THE SUCCESSION PROCESS INTO THE STRATEGIC PLANNING OF A FURNITURE STORES ASSOCIATION}

\begin{abstract}
Djeimi Angela Leonhardt Neske ${ }^{1}$ Emanuel Sandri ${ }^{2}$

\section{RESUMO}

Claudio Antonio Rojo ${ }^{3}$

Inúmeras pesquisas apontam acerca da necessidade de um planejamento para o processo sucessório das empresas, especialmente no que tange a micro e pequenas empresas familiares, visando aumentar a longevidade destas. Contudo, as pesquisas revelam ainda, que mesmo os gestores compreendendo a importância de tal planejamento, poucos o colocam em prática. Este relato tem como objetivo apresentar e analisar as caraterísticas dos gestores associados a uma associação de lojas de móveis - Rede Toklar, propondo-se a confirmar se de fato há indícios de que a implantação do processo sucessório no planejamento da rede é importante e relevante. Em relação à metodologia, trata-se de um estudo de caso aplicado, com pesquisa bibliográfica, documental e pesquisa junto aos gestores. Os resultados são descritivos e indicam que há campo para aprofundar as pesquisas e elaborar uma agenda para a inserção do planejamento sucessório no planejamento estratégico da Rede Toklar. A contribuição do estudo decorre na apresentação de um modelo para que a temática processo sucessório, seja iniciada.
\end{abstract}

Palavras-chave: Planejamento estratégico; Processo sucessório; Empresas familiares; 5W2H.

\begin{abstract}
Numerous researches point to the need for planning for the succession process of companies, especially with regard to micro and small family businesses, in order to increase their longevity. However, surveys also reveal that even managers who understand the importance of such planning are few and far between. This report aims to present and analyze the characteristics of the managers associated with a furniture store association - Toklar Network, proposing to confirm if there are indeed indications that the implementation of the succession process in the network planning is important and relevant. In relation to the methodology, it is an applied case study, with bibliographical research, documentary and research with the managers. The results are descriptive and indicate that there is scope to deepen the research and elaborate an agenda for the insertion of succession planning in the strategic planning of the Toklar Network. The contribution of the study is based on the presentation of a model for the thematic succession process to be started.
\end{abstract}

Keywords: Strategic planning; Succession process; Family businesses; 5W2H.

${ }^{1}$ Mestre em Administração pela Universidade Estadual do Oeste do Paraná - Unioeste. E-mail: djangela2@gmail.com

${ }^{2}$ Mestrando em Administração pela Universidade Estadual do Oeste do Paraná - Unioeste. E-mail: emanuel.sandri@hotmail.com

3 Pós-Doutor em Administração pela Universidade de São Paulo - FEA / USP. Doutor em Engenharia de Produção pela Universidade Federal de Santa Catarina - UFSC. Professor do Programa de Mestrado Profissional em Administração da Universidade Estadual do Oeste do Paraná - UNIOESTE. E-mail: rojo_1970@hotmail.com 


\section{INTRODUÇÃO}

As grandes representantes da economia nacional são as micro e pequenas empresas, tanto pelo número de estabelecimentos, quanto pelo número de empregos formais que representam, sendo $99 \%$ e $52,1 \%$ respectivamente. O comércio é o setor mais representativo em relação ao número de Micro e Pequenas Empresas (MPEs) (Sebrae, 2013). Além de tamanha representatividade, empresas familiares possuem características que lhe são bem peculiares e que as diferenciam das demais, como exemplo geralmente mais marcante, laços e valores entre seus membros (Oliveira, 2006).

A questão do gênero é outro aspecto abordado em relação às empresas familiares. Embora existam empresas geridas por mulheres de forma bem-sucedida, ainda é muito presente no contexto brasileiro, questões acerca do patriarcalismo que por vezes, dificultam ou afastam as mulheres do mercado de trabalho (Martinez Jimenez, 2009).

Tais características peculiares de empresas familiares, quando indexadas ao contexto em que o fundador planeja o processo de sucessão da gestão, pode ser uma variável determinante na longevidade da empresa, desde que inclusa no plano de ação. Tal plano, deve contemplar objetivos e estratégias claras para que todos os envolvidos no processo possam compreender o que se pretende com o processo sucessório (Gonzalez, Sato, Pelissari \& Cid, 2011).

Porém, ainda que estudos apontem a necessidade de tal planejamento, o que ocorre muitas vezes é que a sucessão é pensada, porém, não ocorre um planejamento estruturado para esse processo. Isso ocorre especialmente em pequenas empresas, nas quais há menos propensão do fundador deixar a organização (Santos, Schutz, Sehnem \& Casagrande, 2017). Neste estudo, o modelo de planejamento adotado para as análises é o $5 \mathrm{~W} 2 \mathrm{H}$.

Neste sentido, o objetivo deste estudo é conhecer e analisar as características dos atuais gestores associados a Rede Toklar e compreender se para este público é relevante a inserção do planejamento sucessório no planejamento estratégico da Rede respondendo a seguinte pergunta de pesquisa: As informações pessoais acerca dos gestores, apontam indícios da necessidade da implantação do processo sucessório no planejamento estratégico da associação de lojas de móveis?

O estudo se justifica pelo alto número de empresas familiares que sucumbe por não planejar esse processo e além disso, visando a longevidade tanto das empresas, quanto da Rede Toklar, visto que esta é composta quase integralmente por pequenas empresas familiares.

\section{REFERENCIAL TEÓRICO}

\subsection{Planejamento estratégico}

O planejamento estratégico visa alinhar as ações da organização estabelecidas por seus gestores, pautadas na missão, visão e valores da empresa visando atingir os objetivos propostos, avaliando as oportunidades e problemas internos e externos, analisando seus pontos fortes e fracos (Mintzberg, 1973). Tal planejamento poderá estabelecer períodos de curto, médio e longo prazo. O planejamento estratégico deve ser estabelecido com base em cinco componentes: a) avaliação interna; b) análise ambiental; c) a formulação da estratégia; d) implementação da estratégia; e) o controle estratégico (Fratričová \& Rudy, 2015).

De acordo com Maximiano (2011), as organizações são motivadas a planejar mediante três situações: necessidade ou vontade de intervir na situação atual da empresa ou em prol de 
atingir uma nova realidade; necessidade de afrontar situações futuras ou previsíveis ou não; e coordenar recursos e eventos. O planejamento estratégico, no entanto, trata de definir objetivos e programar as ações a serem executadas, ou seja, a definição do caminho a seguir para alcançar as metas estabelecidas. Neste sentido, Kotler (1999) apresenta um modelo, no qual divide o passo a passo desta elaboração, em etapas, sendo elas: a declaração da visão e missão do negócio; análise do ambiente externo (oportunidades e ameaças); análise do ambiente interno (forças e fraquezas); formulação de metas e serviços; formulação de estratégia; implementação; feedback e controle, vide Figura 1.

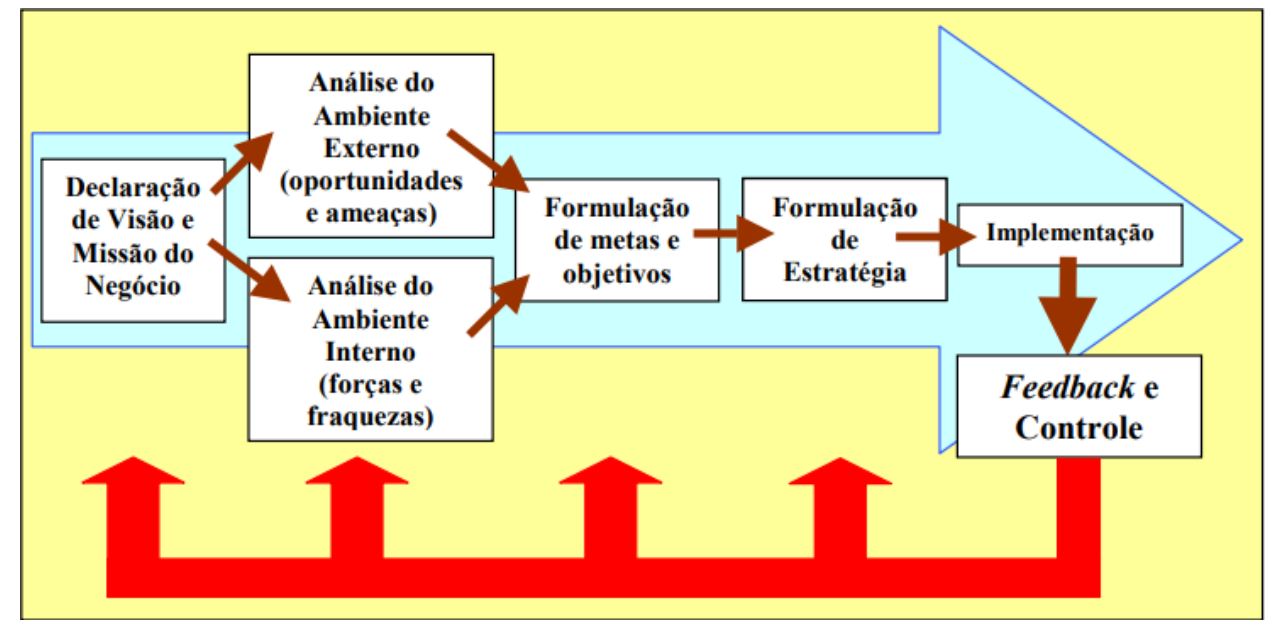

Figura 1. O processo do planejamento estratégico

Nota. Fonte: Kotler, 1999.

Ainda acerca da definição de planejamento estratégico e corroborando com Kotler (1999), Zenaro (2007) aponta que há necessidade de um desenvolvimento claro de uma missão da empresa, definindo seus objetivos, da amplitude dos negócios e da coordenação adequada destas estratégias funcionais. No entanto, somente um bom planejamento estratégico e uma boa gestão, não bastam se estes processos não estiverem voltados para o futuro, explanando ambientes internos e externos, inclusive a futura sucessão, visando mitigar traumas inerentes à troca de liderança (Petry \& Moreira Nascimento, 2009). Os autores ainda evidenciam em seu estudo que a inserção acerca do processo sucessório no planejamento estratégico das empresas é baixa, fato que ocorre inclusive naquelas que já se encontram na terceira e quarta geração.

\subsection{Processo sucessório}

O processo sucessório das empresas é considerado um ponto crítico, com diferentes consequências, inclusive, em muitos casos, resultando no encerramento das atividades da empresa. Dados apontam que somente 30\% das empresas familiares estão na segunda geração e destas, 5\% chegam à terceira (SEBRAE, 2011 apud Richter, 2015). Dados divulgados na pesquisa "As empesas familiares no Brasil" (PWC, 2010) corroboram com os dados do SEBRAE e mostram ainda que no Brasil as pequenas e médias empresas estão mais expostas ao problema de sucessão.

Bortoli Neto e Moreira Jr (2010) também apontam que um elevado número de empresas sucumbe na sucessão de seus gestores, devido especialmente à falta de um planejamento específico para este período. É necessário que haja um bom plano sucessório, este, inclui identificar quem está disposto a ser sucessor, averiguando ainda as competências de gestão e 
avaliar o quão preparado ele está para assumir a gestão da empresa, é desta avaliação que sairá o plano sucessório para a preparação do potencial sucessor (Floriani \& Rodrigues, 2000).

Para que a sucessão ocorra de maneira tranquila é necessário o planejamento de vários fatores, tendo como um facilitador, o processo anterior à transferência da gestão em si. Os fatores abordam o gestor e o sucessor, assim como também o modelo de gestão adotado (Petry \& Moreira Nascimento, 2009). A sucessão deve ser compreendida como um processo, que demanda de tempo para que ocorra a mudança adequada nos papéis que as pessoas exercem (Gersick, Daves, Hampton \& Lansberg, 2006). Neste sentido, quando as empresas elaboram um adequado planejamento para este processo, podem evitar desgastes desnecessários, além de estarem mais aptas para enfrentarem possíveis dificuldades, alavancando deste modo a longevidade do negócio (Meira Teixeira \& Carvalhal, 2013).

\subsection{Ferramenta auxiliar para o planejamento}

Uma ferramenta auxiliar na elaboração do planejamento estratégico, visando o planejamento das ações e o diagnóstico de problemas é a $5 \mathrm{~W} 2 \mathrm{H}$, que é utilizada para diagnosticar problemas e planejar ações. A utilização do quadro facilita o entendimento por meio da definição de métodos, prazos, responsabilidades, objetivos e recursos (Maiczuk \& Andrade Júnior, 2013).

O principal objetivo da ferramenta 5W2H é responder as questões e organizá-las (Veiga, Polacinski, Silva, Tauchen \& Pires, 2013). Permitindo aos envolvidos no processo saber todos os detalhes acerca da execução do plano de ação, inclusive quem é quem, e a razão por estar executando a tarefa que lhe é atribuída (Werkema, 1995). Vide Figura 2.

\begin{tabular}{|c|l|l|l|}
\hline \multirow{4}{*}{$5 \mathrm{~W}$} & What & O que? & Que ação será executada? \\
\cline { 2 - 4 } & Who & Quem? & Quem irá executar/participar da ação? \\
\cline { 2 - 4 } & Where & Onde? & Onde será executada a ação? \\
\cline { 2 - 4 } & When & Quando? & Quando a ação será executada \\
\cline { 2 - 4 } & Why & Por quê? & Por que a ação será executada? \\
\hline \multirow{2}{*}{$2 \mathrm{H}$} & How & Como? & Como será executada a ação? \\
\cline { 2 - 4 } & How much & Quanto custa? & Quanto custa para executar a ação? \\
\hline
\end{tabular}

Figura 2. Ferramenta $5 \mathrm{~W} 2 \mathrm{H}$

Nota. Fonte: Elaborado pelos autores (2017)

\section{METODOLOGIA}

Para atender o objetivo proposto, este relato técnico adotou para o estudo uma abordagem qualitativa com análise descritiva, tipo estudo de caso, por meio de levantamento bibliográfico, visando identificar e descrever características inerentes ao planejamento estratégico nas empresas utilizando 5W2H. A pesquisa em questão é de natureza exploratória e descritiva, pois visa uma atuação prática, no intuito de compreender e descrever as características da empresa analisada (Gil, 2009), para posteriormente propor ações de soluções para possíveis problemas encontrados.

O estudo de caso foi escolhido pois permite que haja uma análise mais profunda e intensa do objeto de estudo (Martins, 2006). A natureza descritiva, por sua vez, é relevante pois permite descrever as características de fatos e fenômenos acerca da população estudada (Gil, 2009), neste caso, os associados da Rede Toklar. 
Considerando a necessidade de impetrar mais informações acerca do universo em estudo, contempla também, objetivo exploratório, visando explorar o tema e proporcionar mais informações e conhecimentos acerca do assunto estudado (Andrade, 2003).

$\mathrm{O}$ acesso aos dados ocorreu de formas variadas: via e-mail; contato telefônico; e especialmente via WhatsApp. No entanto, houve uma reunião presencial no dia 29 de outubro de 2017, momento em que ocorreram as tratativas para a participação da consultora na assembleia da Rede, que ocorreu no dia seguinte. A assembleia permitiu contato da consultora diretamente com os associados. Inicialmente, houve um espaço da assembleia destinado para a explanação geral da proposta da consultoria para os associados, que deliberaram em unanimidade em favor da pesquisa. Posteriormente, ocorreu a aplicação do questionário sobre a caracterização dos gestores que são associados a Rede. Dos 66 associados que a Rede possui, 42 responderam a pesquisa.

Para compreender acerca das características dos gestores, as perguntas decorreram na seguinte ordem: 2.1. Seu gênero, com opção de masculino e feminino; 2.2. Sua idade, com resposta aberta; 2.3. Número de filhos homens e número de filhas mulheres que possui; 2.4 Você é o fundador/a fundadora do negócio? com opção de sim e não; 2.5. Qual a sua formação? Contemplando as opções: fundamental incompleto, fundamental completo; médio incompleto; médio completo; superior incompleto; superior completo; especialização; mestrado/doutorado. As perguntas seguintes foram: 2.6. Número de potenciais sucessores homens e sucessoras mulheres; 2.7. Já identificou o possível sucessor? e, por fim; 2.8. O processo de sucessão já está em andamento?

\section{ANÁLISE E PROPOSTA DE INTERVENÇÕES}

\subsection{Caracterização da Empresa}

A empresa objeto deste estudo tem por nome fantasia Rede Toklar. Trata-se de uma associação de lojas de móveis, eletrodomésticos e afins, sendo o setor de móveis, o principal. A central administrativa da rede situa-se na cidade de Ijuí - RS. Fundada em 2002, seu foco consiste em oferecer benefícios aos seus associados, parceiros e clientes, por meio da cooperação. Atualmente, a associação conta com 66 associados que ao todo, possuem 118 lojas, abrangendo os estados do Rio Grande do Sul, Santa Catarina, Paraná e Mato Grosso do Sul.

A estrutura do organograma funcional da Rede é apresentada na Figura 3. Percebe-se por meio do organograma que a Rede se preocupa em planejar ações em várias frentes de trabalho, são elas: Equipe de negociação; Equipe estratégica; Equipe de marketing; e Equipe de expansão com equipes específicas para atender as demandas a elas relacionadas.

O objetivo da equipe de negociação está pautado no aumento das compras em conjunto, de $10 \%$ ao ano até 2019 . A equipe é composta por doze integrantes, sendo a equipe com maior número, destes, onze são associados e um, colaborador do centro administrativo. Esta equipe visa alinhar os produtos que serão negociados via rede, no intuito de atender os anseios e necessidades dos associados das diferentes regiões. Para a realizar as atividades, há uma agenda semanal fixa, com reuniões virtuais, via Skype.

A equipe estratégica tem o objetivo traçado visando profissionalizar a gestão da Rede no período 2016-2019. É composta por quatro associados mais um membro do centro administrativo e tem uma agenda mensal de reuniões virtuais.

Já a equipe de marketing, visa contemplar as ações de marketing para todas as lojas até 2019. Ela é composta por nove associados mais um membro do centro administrativo e conta 
com reunião quinzenal, também de modo virtual. Cabe frisar, que esta equipe conta com o apoio de uma agência de publicidade, que é quem executa as demandas.

A Equipe de expansão por sua vez, volta seus esforços para atingir a meta de 150 lojas associadas até 2019 e conta com reunião virtual a cada trinta dias.

O centro administrativo, possui 5 colaboradores que atendem as demandas de todas as equipes e também diretoria. A diretoria é composta por 7 membros, que mantém agenda mensal fixa de reuniões virtuais. Os conselhos fiscal e de ética, são compostos por 5 membros cada, que se reúnem de acordo com as demandas apresentadas. Todos os membros são eleitos para mandato de 2 anos.

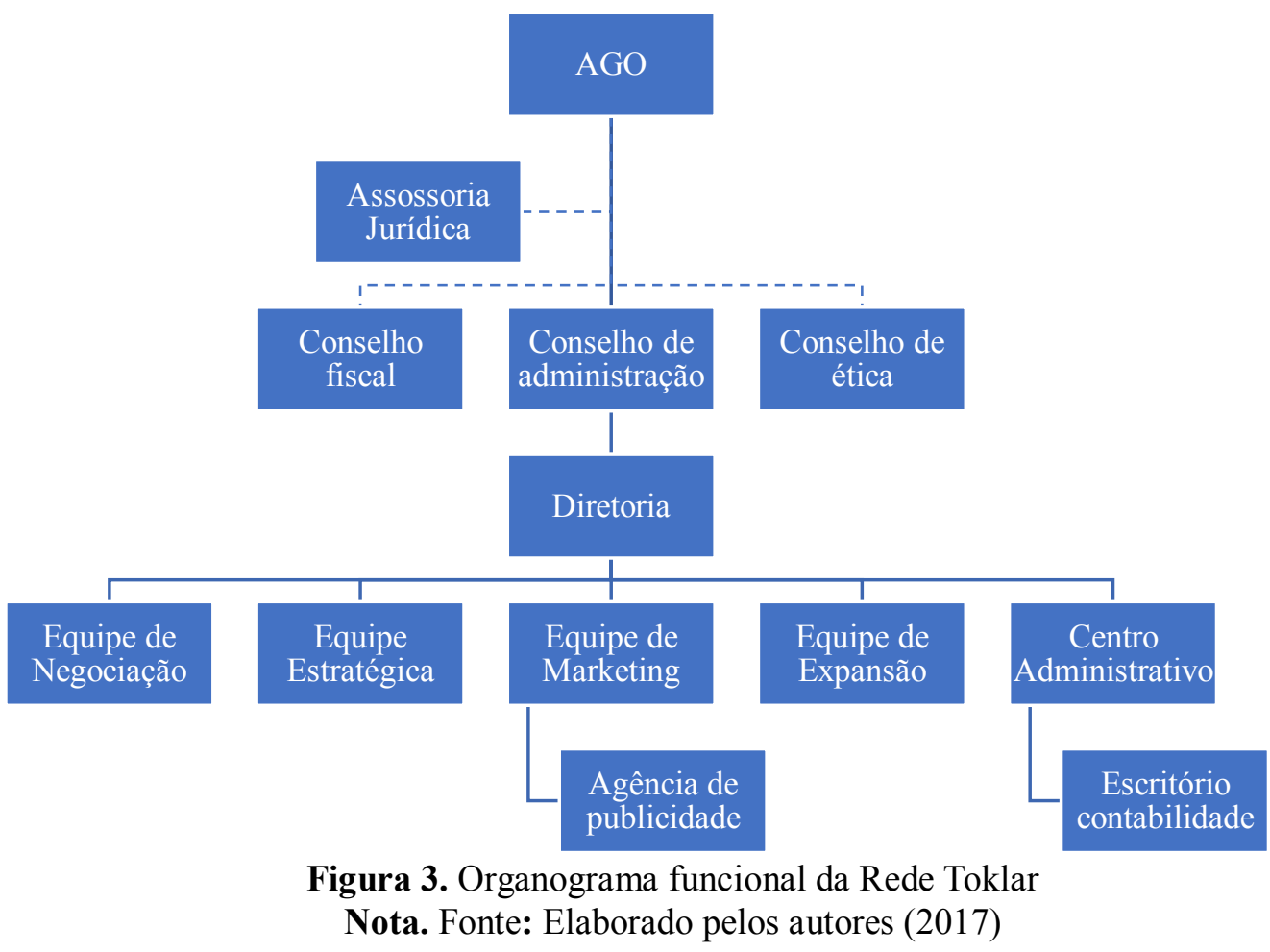

\subsection{Diagnóstico}

Tendo acesso às informações do Planejamento Estratégico 2016-2019 da Rede Toklar foi possível avançar nas análises. O modelo utilizado pode ser enquadrado na proposta apresentada por Kotler (1999), contempla missão "Unir e desenvolver as empresas integrantes da rede, buscando resultados que satisfaçam interesses dos associados, parceiros e clientes"; visão "Marca forte no comércio de móveis e eletrodomésticos e líder na região em que atua"; e ainda os valores: "transparência e ética; responsabilidade e confiança; respeito ecológico; honestidade e respeito às pessoas; participação, comprometimento e comunicação; cooperação e fidelidade".

A diretriz estratégica decorre visando o objetivo de fortalecer as empresas associadas à rede. Na sequência, é apresentada a matriz SWOT a qual apresenta as forças e fraquezas (ambiente interno) e oportunidades e ameaças (ambiente externo), etapa também inclusa no modelo de Kotler (1999). A matriz é reavaliada periodicamente, sendo o trabalho coordenado pelo supervisor da rede, com consulta aos associados em reuniões específicas com os representantes das equipes apresentadas na Figura3. 
Para a formulação de metas, objetivos e estratégias, que correspondem à terceira fase do modelo de Kotler (1999) (Figura 1), a rede faz uso da ferramenta 5W2H. O intuito de sua utilização pela rede, ocorre no sentido de facilitar e identificar das atividades e dos respectivos responsáveis, servindo ainda como uma ferramenta de gestão visualmente prática, facilitando o repasse das informações ao conhecimento dos demais associados, características que corroboram com as apresentadas por (Maiczuk \& Andrade Júnior, 2013).

$\mathrm{O}$ quadro $5 \mathrm{~W} 2 \mathrm{H}$ é elaborado por cada uma das equipes. Para cada equipe, há o objetivo definido e o detalhamento é feito no quadro. Porém, observou-se que em nenhum dos casos, a ferramenta é utilizada completamente, as questões não respondidas pelas equipes, referem-se ao quinto $\mathrm{H}$, ou seja, não responderam o "Por quê?" de cada ação estabelecida e segundo $\mathrm{H}$, que diz respeito ao "Quanto custa?".

As equipes de negociação, de marketing e de expansão, utilizam 4W1H, sendo eles: $\mathrm{O}$ que?; Quem? Onde? Quando?; e 1H: Como?. Já a equipe estratégica, apresenta os itens "O que?, Onde? Como?", ou seja, 2W1H.

Ainda que existam as falhas em relação a plena utilização da ferramenta adotada, é perceptível a preocupação da rede em todas as áreas, demostrando ainda atender a missão, visão e valores estabelecidos por ela. Entretanto foi identificada uma lacuna no tocante ao planejamento sucessório das empresas associadas.

\subsection{Caracterização dos gestores}

Dificuldades identificadas acerca do processo sucessório, indicam que grande parte está relacionada com a figura do fundador ou atual gestor da empresa, que pode ter pouco conhecimento acerca do processo para elaborar um plano de sucessão, ou até mesmo ter resistência em relação ao assunto (Bortoli Neto \& Moreira Jr, 2010).

Considerando o atual gestor como ator principal do processo, o primeiro passo dado no sentido de aferir sobre a proposta de intervenção é conhecer mais acerca dessas importantes figuras. A primeira fase, consistiu em confirmar se de fato há indícios de que a implantação do processo sucessório pode ser relevante. Tais indícios foram aferidos por meio da pesquisa com as questões apresentadas no final do item 3 , metodologia. seguir.

A pesquisa contou com 42 respondentes e os principais achados, são apresentados a

Quanto ao gênero, $37(88,1 \%)$ correspondem ao masculino, sendo o feminino representado por apenas $5(11 ., 9 \%)$ dos respondentes. Esse resultado corrobora com o modelo de família patriarcal e nuclear, em que o homem ainda é representado como provedor da família e com autoridade incontestável, sendo o modelo que construiu as relações políticas e sociais em nosso país (Holanda, 2004).

Tal aspecto pode ainda decorrer da diferença na socialização entre filhos e filhos, no âmbito de que os filhos, especialmente os primogênitos são incentivados ao envolvimento nos negócios, enquanto as filhas, passam menos tempo na empresa, reduzindo assim o número de habilidades gerenciais (Martinez Jimenez, 2009). Ainda em relação ao gênero, Albuquerque, Pereira \& Oliveira, 2014, puderam evidenciar predomínio de valores patriarcais nos negócios familiares, cabendo ao filho homem preparar-se para assumir os negócios da família.

A segunda questão, visou identificar a idade dos gestores. A maioria dos gestores encontram-se nas faixas de 41 até 50 anos e de 51 até 60 anos, que juntos correspondem a $61,90 \%$ dos gestores. Representando neste sentido, uma idade em que ainda há um tempo adequado para planejar o processo sucessório adequadamente. A faixa etária geral dos gestores 
é: até 30 anos, 2 (4,76\%); de 31 a 40 anos, $7(16,67 \%)$; de 41 a 50 anos, $15(35,71 \%)$; de 51 até 60 anos, 11 (26,19\%); de 61 até 70 anos, 6 (14,29\%); acima de 70 anos, $1(2,38 \%)$.

Em relação ao número de filhos e filhas que os gestores possuem, em valores absolutos há predominância de filhas mulheres, que representam um total de 55 filhas enquanto o total de filhos corresponde a 35. Já em porcentagem, a mais significativa diz respeito a respondentes que não tem nenhum ou apenas um filho homem, ambos com 40,48\%.

\section{Tabela 1}

Quantidade e gênero de filhos por gestor respondente

\begin{tabular}{|c|c|c|c|}
\hline Quantidade de filhos homens & Frequência & Porcentagem & Absoluto \\
\hline 0 & 17 & $40,48 \%$ & 0 \\
\hline 1 & 17 & $40,48 \%$ & 17 \\
\hline 2 & 7 & $16,67 \%$ & 14 \\
\hline 4 & 1 & $2,38 \%$ & 4 \\
\hline Total & 42 & 100,00 & 35 \\
\hline Quantidade de filhas mulheres & Frequência & Porcentagem & Absoluto \\
\hline 0 & 10 & $23,81 \%$ & 0 \\
\hline 1 & 15 & $35,71 \%$ & 15 \\
\hline 2 & 12 & $28,57 \%$ & 24 \\
\hline 3 & 4 & $9,52 \%$ & 12 \\
\hline 4 & 1 & $2,38 \%$ & 4 \\
\hline Total & 42 & 100,00 & 55 \\
\hline
\end{tabular}

Nota. Fonte: Elaborado pelos autores (2017)

Quando perguntados se são os fundadores do negócio, o resultado encontrado foi de 23 $(54,8 \%)$ de fundadores e $19(45,2 \%)$ de não fundadores. A diferença encontrada não é muito significativa, no entanto ainda prevalecem os fundadores. Com acesso a dados complementares, foi possível verificar que dos 19 gestores que não foram fundadores do negócio, apenas um, se encontra na terceira geração, ou seja, exceto por esse, os demais precisarão enfrentar o processo sucessório pela primeira ou segunda vez.

De certa forma, isso pode ser até mais complexo, pois neste caso, não há experiência no processo sucessório e existem mais familiares envolvidos, essa fase é denominada consórcio de primos. Depois da primeira geração além da alteração dos proprietários, ocorre também alteração na forma de propriedade, que tende a ser mais diluída, podendo ser assim classificada: a) único proprietário, sendo controlada por um dono ou pelo casal; b) sociedade entre irmãos: ocorre geralmente na segunda geração, pertencendo a um ou mais irmãos; c) consórcio de primos: atingido na terceira geração, quando primos de diferentes ramos podem assumir o negócio (Gersick et al., 2006).

Em relação a formação dos respondentes, a metade deles, 50\%, tem ensino superior completo, seguido daqueles que possuem ensino médio completo. Os dados na íntegra representam os seguintes valores: Fundamental completo, 4 (9,52\%); médio incompleto, 1 (2,38\%); médio completo, $11(26,19 \%)$; superior incompleto, 3 (7,14\%); e superior completo, $21(50 \%)$

No tocante à identificação da quantidade e do gênero de potenciais sucessores, a maior porcentagem encontra-se em gestores que ainda não identificaram nenhum potencial sucessor, independente de gênero. Em valores absolutos, há uma pequena diferença positiva em relação 
ao número de homens identificados, no entanto, quando esse dado é comparado ao número de filhos, a diferença passa a ser mais significante, pois, ainda que os gestores possuam menos filhos homens, 35 e mais mulheres, 55 (Tabela 1), na Tabela 2, há identificação de mais potenciais sucessores do gênero masculino.

Neste sentido, cabe aprofundar as averiguações acerca do tema para identificar se os dados corroboram com o que aponta Martinez Jimenez (2009) ou o que leva a tais resultados.

\section{Tabela 2}

Quantidade e identificação do gênero de potencias sucessores identificados

\begin{tabular}{cccc}
\hline $\begin{array}{c}\text { Quantidade potenciais sucessores } \\
\text { homens }\end{array}$ & Frequência & Porcentagem & Absoluto \\
\hline 0 & 15 & $35,7 \%$ & 0 \\
1 & 14 & $33,3 \%$ & 14 \\
2 & 11 & $26,2 \%$ & 22 \\
4 & 2 & $4,8 \%$ & 8 \\
Total & $\mathbf{4 2}$ & $\mathbf{1 0 0 , 0}$ & $\mathbf{4 4}$ \\
\hline Quantidade potenciais sucessoras & Frequência & Porcentagem & Absoluto \\
mulheres & & & 0 \\
\hline 0 & 18 & $42,9 \%$ & 13 \\
1 & 13 & $31,0 \%$ & 18 \\
2 & 9 & $21,4 \%$ & 3 \\
3 & 1 & $2,4 \%$ & 4 \\
4 & 1 & $2,4 \%$ & $\mathbf{3 8}$ \\
Total & $\mathbf{4 2}$ & $\mathbf{1 0 0 , 0}$ &
\end{tabular}

Nota. Fonte: Elaborado pelos autores (2017)

No entanto, é preciso considerar que a maioria dos gestores ainda não identificou os possíveis sucessores para o negócio, sendo assim, difícil afirmar que se trata apenas de questão de gênero. O item 2.7 apresentado no método indica que apenas $16(38,10 \%)$ dos gestores já identificaram o potencial sucessor para o seu negócio. Dado ao elevado número de gestores que ainda nem sequer identificou os possíveis sucessores, é relevante que o assunto comece a ser debatido no âmbito da Rede e passe a ser contemplado no planejamento estratégico.

Outro dado que corrobora com a necessidade da implantação do tema se refere ao item 2.8 do método, em que as respostas apontam que em apenas 11 casos, ou seja, 26,19\% das empresas, o processo já está em andamento. Sendo assim, dos 16 gestores que identificaram sucessores, em 11 casos o processo está em andamento, restando apenas 5 gestores que deram o primeiro passo, em relação ao processo, porém, há um universo de $61,90 \%$ gestores que necessitam planejar desde o primeiro passo.

\subsection{Proposta de Intervenção}

Percebendo o quão complexo o processo sucessório é para as empresas familiares a ponto de ser considerada a situação mais complexa e crítica enfrentada pela empresa (De Massis et al., 2008; Bortoli Neto \& Moreira Jr, 2010; Meira Teixeira \& Carvalhal, 2013) e levando em consideração que se trata de um processo de longo prazo, mas que pode aumentar a longevidade do negócio (Meira Teixeira \& Carvalhal, 2013), a proposta de intervenção é: 
1) Propor uma agenda de inclusão referente ao processo sucessório no Planejamento Estratégico da Rede.

O intuito da proposta é que ela seja implantada gradativamente e com suporte da Rede aos seus associados, visando a longevidade destes e também da Rede, uma vez que esta é composta em sua maioria por empresas familiares. Sendo a rede uma associação que visa a cooperação e a longevidade de seus associados e de sua própria organização e de acordo com os resultados observados, é relevante e inclusão do processo sucessório no âmbito da Rede.

A proposta inicial é de que se utilize a ferramenta $5 \mathrm{~W} 2 \mathrm{H}$, que já é conhecida pelos gestores, para inserir ao assunto na pauta das equipes gradativamente. A proposta detalhada é apresentada na Tabela 3. No entanto, há necessidade da realização de uma pesquisa mais aprofundada em relação aos gestores e também das empresas, para posteriormente elaborar uma agenda mais detalhada de como a Rede pode intervir o orientar seus associados neste delicado processo de transição.

\begin{tabular}{|c|c|c|c|c|c|c|}
\hline $\begin{array}{c}\text { What } \\
\text { (O que?) }\end{array}$ & $\begin{array}{c}\text { Who } \\
\text { (Quem?) }\end{array}$ & $\begin{array}{l}\text { Where } \\
\text { (Onde?) }\end{array}$ & $\begin{array}{c}\text { When } \\
\text { (Quando?) }\end{array}$ & $\begin{array}{c}\text { Why } \\
\text { (Por quê?) }\end{array}$ & $\begin{array}{c}\text { How } \\
\text { (Como?) }\end{array}$ & $\begin{array}{c}\text { How much } \\
\text { (Quanto } \\
\text { custa?) }\end{array}$ \\
\hline $\begin{array}{c}\text { Inserção do } \\
\text { processo } \\
\text { sucessório } \\
\text { no } \\
\text { planejament } \\
\text { o estratégico } \\
\text { da Rede }\end{array}$ & $\begin{array}{c}\text { Equipe } \\
\text { estratégic } \\
\mathrm{a}\end{array}$ & $\begin{array}{c}\text { Central } \\
\text { administrativa }\end{array}$ & $\begin{array}{l}\text { Fevereiro } \\
\text { de } 2018 . \\
\text { Evoluindo } \\
\text { em cada } \\
\text { reunião } \\
\text { até } \\
\text { setembro } \\
\text { de } 2018\end{array}$ & $\begin{array}{c}\text { Visando a } \\
\text { longevidade } \\
\text { das empresas e } \\
\text { da própria rede } \\
\text { por meio de } \\
\text { um processo } \\
\text { planejado } \\
\text { adequadamente }\end{array}$ & $\begin{array}{c}\text { Iniciando as } \\
\text { tratativas } \\
\text { dentro da } \\
\text { equipe, } \\
\text { abrangendo } \\
\text { posteriormente } \\
\text { os associados }\end{array}$ & $\begin{array}{c}\text { Apenas } \\
\text { investimento } \\
\text { em tempo } \\
\text { para tratar } \\
\text { do assunto }\end{array}$ \\
\hline $\begin{array}{c}\text { Implantação } \\
\text { do processo } \\
\text { sucessório } \\
\text { nas lojas } \\
\text { associadas }\end{array}$ & $\begin{array}{c}\text { Equipe } \\
\text { estratégic } \\
\mathrm{a}\end{array}$ & $\begin{array}{c}\text { Apresentar } \\
\text { proposta na } \\
\text { A.G.O. } \\
\text { Gradativament } \\
\text { e em lojas } \\
\text { associadas }\end{array}$ & $\begin{array}{l}\text { Setembro } \\
2018\end{array}$ & $\begin{array}{l}\text { Minimizar } \\
\text { impactos } \\
\text { inerentes ao } \\
\text { processo } \\
\text { sucessório }\end{array}$ & $\begin{array}{l}\text { Com apoio em } \\
\text { dados da } \\
\text { pesquisa (que } \\
\text { deve ser mais } \\
\text { aprofundada), } \\
\text { da central } \\
\text { administrativa } \\
\text { e com ajuda } \\
\text { de consultor } \\
\text { externo (se } \\
\text { necessário) }\end{array}$ & $\begin{array}{c}\text { Varia de } \\
\text { acordo com } \\
\text { a } \\
\text { necessidade } \\
\text { de cada loja }\end{array}$ \\
\hline
\end{tabular}

Figura 4. 5W2H processo sucessório

Nota. Fonte: Elaborado pelos autores (2017)

\section{CONCLUSÃO}

O objetivo deste estudo foi apresentar e analisar a caracterização dos gestores associados a Rede Toklar. No entanto, antes da caracterização dos associados, foi preciso compreender a estrutura da rede e seu funcionamento. Em relação ao diagnóstico da Rede, é possível afirmar que há constante preocupação com todos os stakholders e que a estrutura organizacional da mesma, demonstra seriedade e compromisso com a gestão. A utilização de ferramentas administrativas como $5 \mathrm{~W} 2 \mathrm{H}$, favorece o planejamento estratégico especialmente no tocante ao rompimento das barreiras geográficas que existem entre os associados.

Com o uso das tecnologias e ferramentas adequadas, a Rede possibilita que gestores dos quatro estados estejam diretamente envolvidos na elaboração do planejamento estratégico e 
demais demandas que podem surgir, essa experiência de gestão virtual, pode ser considerada um aspecto positivo para a inclusão do processo sucessório na gestão.

Quanto à proposta de intervenção, aponta-se o primeiro passo a ser dado, que é de incluir $\mathrm{o}$ assunto junto às equipes evidenciadas na Tabela 3 , por meio da ferramenta $5 \mathrm{~W} 2 \mathrm{H}$. No entanto, para uma agenda mais detalhada sobre a proposta há necessidade de mais investigações e também uma consulta efetiva aos associados frente ao interesse de tal intervenção.

Apesar da limitação decorrente pela ausência de retorno de 24 respondentes, os resultados fornecem os indícios necessários acerca da necessidade e relevância da inserção do processo sucessório no planejamento da rede.

As investigações futuras devem decorrer no sentido de investigar se de fato ocorre o predomínio de valores patriarcais; a influência dos laços familiares no processo sucessório; investigação mais profunda acerca dos gestores e características dos possíveis sucessores para a elaboração da agenda de intervenção e ainda, a sucessão da gestão e da propriedade.

A principal contribuição do estudo decorre no sentido de apontar a necessidade do processo sucessório para os associados da Rede Toklar, evoluindo com a apresentação inicial de um modelo adaptado à uma ferramenta que já é de uso comum para a rede e seus associados, viabilizando que o assunto comece a ser debatido e posteriormente implantado gradativamente nas empresas.

\section{REFERÊNCIAS}

Albuquerque, A. L., Pereira, R. D., \& de Oliveira, J. L. (2014). Sucessoras invisíveis: o impacto das questões de gênero nos processos de sucessão em empresas familiares. Gestão \& Planejamento-G\&P, 15(2).

Andrade, M. M. de. (2003). Introdução à metodologia do trabalho científico. 6.ed. São Paulo: Atlas.

Bortoli Neto, A., \& Moreira, Jr. A. L. (2010). Dificuldades para a realização da sucessão: um estudo em empresas familiares de pequeno porte. REGE Revista de Gestão, 8(4).

De Massis, A., Chua, J. H., \& Chrisman, J. J. (2008). Factors preventing intra-family succession. Family Business Review, 21(2), 183-199.

Santos, A. A. P. dos, Schutz, E. M., Sehnem, S., \& Casagrande, J. L. (2017). Family succession: analysis of Brazilian writings from the period between 2004 and 2015. Revista Brasileira de Estratégia, 10(1), 150.

Floriani, O., \& Rodrigues, L. C. (2000). Sucessão empresarial: processo sucessório em empresas familiares. Encontro de Empreendedorismo e Gestão de Pequenas Empresas, I.

Fratričová, J., \& Rudy, J. (2015). Get Strategic Human Resource Management ReallyStrategic: Strategic HRM in Practice. InternationalJournalof Management Cases, 17(4).

Gersick, K. Daves, J. A., Hampton, M. M., Lansberg, I. (2006). De geração para geração: ciclos de vida das empresas familiares. Rio de Janeiro: Elsevier. 
Gil, A. C. (2009). Como elaborar projetos de pesquisa. 4. ed. São Paulo: Atlas.

Gonzalez, I. V. D. P., Sato, A. C. L., Pelissari, A. S., \& Cid, B. G. (2011). Plano de sucessão: um estudo de caso em uma empresa familiar de mídia exterior. Revista de Negócios, 16(4), 51-75.

Holanda, S. B.de. (2004). Raízes do Brasil. São Paulo: Companhia das Letras.

Kotler, P. (1999). Marketing para o século XXI: como criar, conquistar e dominar mercados. Futura.

Maiczuk, J., \& Andrade Júnior, P. P. (2013). Aplicação de ferramentas de melhoria de qualidade e produtividade nos processos produtivos: um estudo de caso. Qualitas Revista Eletrônica, 14(1).

Martinez Jimenez, R. (2009). Research on women in family firms: Current status and future directions. Family Business Review, 22(1), 53-64.

Martins, G. A. de. (2006). Estudo de caso: uma estratégia de pesquisa. São Paulo: Atlas.

Maximiano, A. C. A. (2011). Introdução à administração. 8 Ed. Atlas.

Meira Teixeira, R., \& Carvalhal, F. (2013). Sucessão e conflitos em empresas familiares: estudo de casos múltiplos em empresas na cidade de Aracaju. Revista Alcance, 20(3).

Mintzberg, H. (1973). Strategy-making in three modes. California management review, 16(2), 44-53.

Oliveira, D. de P. R. (2006). Empresa familiar: como fortalecer o empreendimento e otimizar o processo sucessório. 2.ed. São Paulo: Atlas.

Petry, L. I., \& Moreira Nascimento, A. (2009). Um estudo sobre o modelo de gestão e o processo sucessório em empresas familiares. Revista Contabilidade \& Finanças-USP, 20(49).

PWC - PricewaterhouseCooperes. As empresas familiares no Brasil: pesquisa 2010.

Disponível em: <http://www.pwc.com.br>. Acesso em: 19 ago. 2017.

Richter, J. (2015). Planejamento sucessório de empresas familiares: uma análise de empresas de pequeno e médio porte sob a perspectiva do fundador.

Sebrae (2013). Sobrevivência das Empresas no Brasil. Brasília.

Veiga, R. S., Polacinski, É., Silva, V. B., Tauchen, J., \& Pires, M. R. (2013). Implantação dos 5Ss e proposição de um SGQ para uma indústria de erva-mate. Revista ADMpg Gestão estratégica, 6(1), 71-78. 
Werkema, M. C. C. (1995). As ferramentas da qualidade no gerenciamento de processos. As ferramentas da qualidade no gerenciamento de processos. Editora DG.

Zenaro, M. (2007). Marketing para empreendedores: o segredo do sucesso. UNOESC. 